This item was submitted to Loughborough's Research Repository by the author.

Items in Figshare are protected by copyright, with all rights reserved, unless otherwise indicated.

\title{
A comparison of three materials used for tactile symbols to communicate colour to children and young people with visual impairments
}

PLEASE CITE THE PUBLISHED VERSION

http://dx.doi.org/10.1177/0264619615610161

\section{PUBLISHER}

(C) The Authors. Published by SAGE Publications

\section{VERSION}

AM (Accepted Manuscript)

\section{PUBLISHER STATEMENT}

This work is made available according to the conditions of the Creative Commons Attribution-NonCommercialNoDerivatives 4.0 International (CC BY-NC-ND 4.0) licence. Full details of this licence are available at: https://creativecommons.org/licenses/by-nc-nd/4.0/

\section{LICENCE}

CC BY-NC-ND 4.0

\section{REPOSITORY RECORD}

Ramsamy-Iranah, Sabrina, Martin Maguire, James A. Gardner, Satyadev Rosunee, and Naraindr Kistamah. 2019. "A Comparison of Three Materials Used for Tactile Symbols to Communicate Colour to Children and Young People with Visual Impairments". figshare. https://hdl.handle.net/2134/20746. 


\title{
A comparison of three materials used for tactile symbols to communicate colour to children and young people with visual impairments
}

\begin{abstract}
A series of 14 tactile symbols were developed to represent different colours and shades for children and young people who are blind or have visual impairment. A study compared three different methods for representing the symbols: (1) embroidered thread, (2) heated 'swell' paper, and (3) representation in plastic using Additive Manufacturing (3D-printing). The results show that for all three materials, the recognition of particular symbols varied between 2.40 and 3.95 seconds. The average times for the three materials across all colours was $2.26 \mathrm{~s}$ for AM material, $3.20 \mathrm{~s}$ for swell paper and $4.03 \mathrm{~s}$ for embroidered symbols. These findings can be explained by the fact that the AM material (polylactide) is firmer and more easily perceived tactually than the other two materials. While AM plastic offers a potentially useful means to communicate colours for appropriate objects, traditional media are still important in certain contexts.
\end{abstract}

\section{Keywords}

Colour symbols, visual impairment, blindness, embroidery, swell paper, Additive Manufacturing, 3D printing. 


\section{Introduction}

About five percent of world cases of visual impairment involve young people of less than 15 years old (Steinkuller, Du, and Gilbert, 1999). The World Health Organisation has reported that globally about 1.4 million young people are blind and/or visually impaired (WHO, 2014).

Having a means to communicate the colour of objects to blind or visually impaired young people is an important topic for several reasons: colour is an important way to talk about objects both in the school and the home environment; they hear about colours; they wear colours; and it enables them to share colour experiences with sighted people. Hence the need was identified to create a symbol language to represent colour for children and young people. If young people are able to engage with the world of colour, this will help them to be more accurate and efficient with daily activities and become more selfreliant (for example, making a quick choice of clothing of a certain colour), to assist with and enrich learning (e.g. discussing a work of art) or to take part in leisure activities (e.g. playing a game with coloured pieces). People with visual impairments also have different concepts of colour. Someone who is congenitally blind will know the terms for colour, but it is a more abstract means of classification. For those who have lost their sight during their lives, or those who have some perception of light and colour, they will have an understanding of the meaning of different colours and their associations in everyday life.

Tactile language systems such as Braille exist to support communication for visually impaired people. Items such as Braille clothing tags are available commercially (Future Aids, 2015). However it is not necessarily the ideal language for communicating colours. A pattern of dots on a clothing tag can be a lengthy way to spell out, for example, 'dark blue'. It is also necessary to ensure that the tag is held the right way up for it to be interpreted. Some visually impaired people may prefer not to learn Braille but 
still need a scheme to show the colours of objects such as clothing, to make sure they don't clash, or toy bricks to help a child construct a realistic model e.g. red bricks on a green base with a blue overlay to create a model house within a garden and pond.

A research project has developed a series of symbols to represent different colours and shades for use by children and young people with visual impairment and blindness. This includes 9 main colours and 5 tonal variations. This paper is concerned with the effectiveness of different materials or media by which the Colour Symbol Set (CSS) can be communicated.

The initial part of the paper looks at research done on the significance of texture and tactile relief in symbols, the activity of memorisation and haptic memory, and their use in 3D forms. The second part describes the creation of the CCS based on principles from the literature, while the third part covers the production of the symbols for testing using three materials: 'swell' paper, embroidered fabric and Additive Manufacturing (AM) plastic. Thirdly a comparative study of all three materials tested by 27 visually impaired young participants is reported and conclusions drawn.

\section{Study aims}

The aims of the study were:

- To compare the performance of a sample of children and young people in recognizing tactile colour symbols (using the CSS) when presented in three different materials.

- To identify differences in performance across three age groups.

- To generate some recommendations for selecting the most suitable material for creation of tactile colour symbols for different purposes. 


\section{Literature review}

Size of Tactile Symbols

Tactile symbols are classified into three types: line symbols that designate boundaries of lines; textured symbols that show areas; and point symbols to indicate precise location (Kops and Gardner, 1996). There are certain factors that influence tactile symbols such as the elevation (or vertical height), size, shape and texture, orientation, and stimulus redundancy.

The elevation of symbols is important when trying to identify them by touch. The more pronounced the height, the more easily distinguished are the points, areas and line symbols. Loomis and Lederman (1986) defined the accuracy of tactile recognition of raised characters by five variables;

- Height of upper surface in relation to the base (elevation)

- Symbol set (use of familiar and identifiable shapes)

- Spatial extent of the symbols (size)

- Mode of touch (static and moving)

- $\quad$ Contact force

The size of a tactile symbol should be relatively larger than a visual symbol to be as easily recognised. Similarly forms like solid and outline circles, and triangles were tested for their tactile sensibility (Perera, 2002). The outlined shapes were more accurately distinguished 
than solid or punctuate symbols (Figure 1). It can be deduced that while using the fingertip, an outline shape is more easily perceived by giving a better feel of the edges round it.

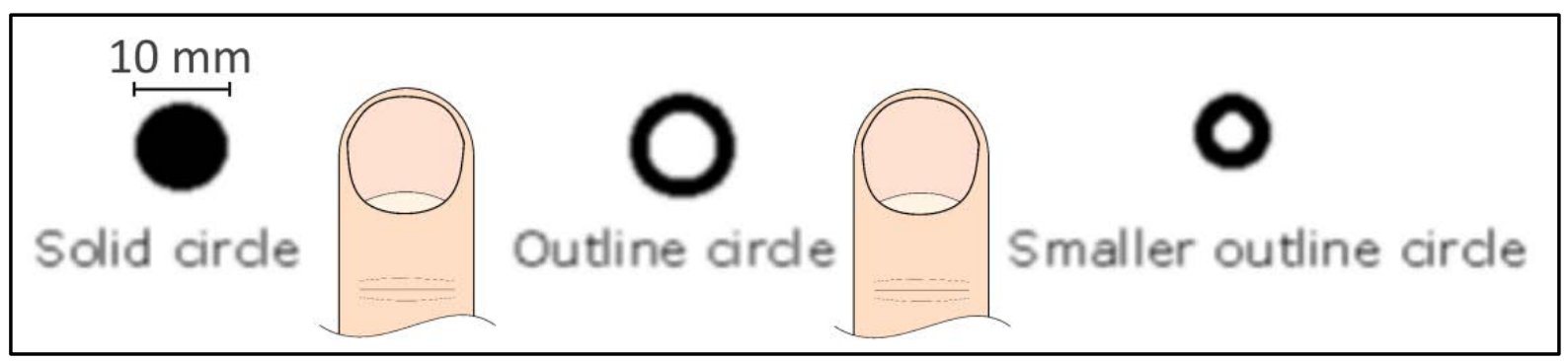

Figure 1. Presenting a symbol in outline and a larger size makes it easier to recognise.

The resolution of peripheral mechanoreceptive units is approximately $1 \mathrm{~mm}$, however $10 \mathrm{~mm}$ $\mathrm{x} 10 \mathrm{~mm}$ is the minimum physical size needed for a tactile display (Pawluk, Buskirk, and Killbrew, 1998; Perera, 2002).

Stevens and Foulke (1996) reported that the spatial acuity of the skin on the fingertips deteriorates with age. He determined the average thresholds as follows;

- Young $(18-33$ years $)=1.95 \mathrm{~mm}$

- Middle-aged $(41-63$ years $)=2.68 \mathrm{~mm}$

- Elderly $(66-91$ years $)=5.03 \mathrm{~mm}$

The two types of tactile stimuli that people use for interaction are passive and active touch (Chapman, 1994). Passive touch is the 'stationary movement' of the fingertips on a surface 
whereas active touch is the 'scanning movement' of the fingertips. Some tactile features can be read through touch without any friction caused by movement.

\section{Texture in $3 D$ symbols}

Texture is essential for the identification of a symbol by tactile means. It provides information on the materials used and the differentiation from the base and printed symbol. According to Kops and Gardner (1996) textures are defined by the dot or pixel density, spacing and angular orientation. The patterns of vertical and horizontal symbols are easier to distinguish than diagonal or diamond-shaped ones which can be confusing as the density of the texture increases. Vertical and horizontal patterns relate to the interaction between the orientation of textures and direction of movement across the skin (Kops and Gardner, 1996). Orientation together with density is easier to distinguish than density alone. Perera (2002) reported that textures are distinctive when their elements are closely spaced on one axis but distantly spaced along the other two axes (Figure 2).

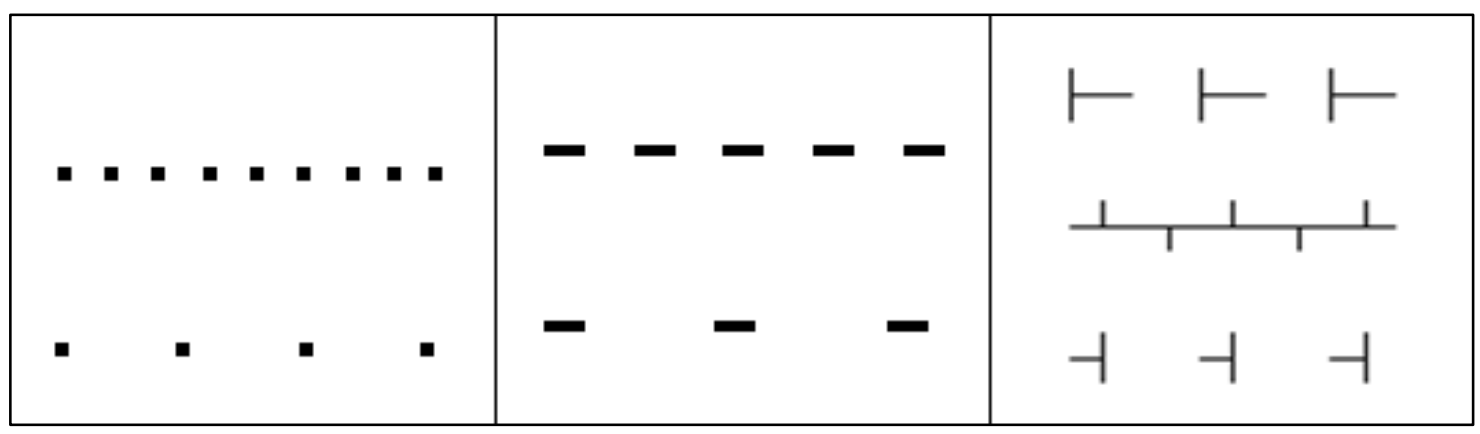

Figure 2. Increasing the density and including multiple orientations of symbols helps improve recognition. 
Memorizing 3D symbols

Gual, Puyuelo, and Llovras (2014) tested 3D symbols to determine how easy or difficult they were to memorise. They looked at the activity of both the haptic memory and the short term memory of blind people to retain the symbols' information (referred to by Millar and Al-Attar, 2003). They found that previous experience with tangible graphics helped to explore a tactile device efficiently, while group shape similarity was a useful design strategy to help store data through touch. (This is also referred to by Todorovic, 2008). Different types of symbols and keys in relief are commonly used in maps so that they can be recognised by touch. According to Gual et al. (2014), referring to a statement by Perkins (2002), there are no international standards for tactile symbols. However, there are manuals and guidelines with regard to design requirements, which specify that tactile symbols should be clearly distinguished from each other to facilitate memorisation (Edman, 1992; Gual et al., 2014). There are some factors like size, shape and contrast that also influence the ease of distinguishing tactile symbols and so to design a comprehensive tactile symbol, the designer should consider a suitable size, simple shapes, and contrasting symbols with differences in terms of height, texture and the concavity or convexity of relief (Gardner and Perkins, 2002; Gual et al., 2014).

Haptic interfaces for presenting information

Haptic interfaces such as the 3D pin tactile displays designed by Shimojo, Shinohara, and Fukui (1998) enable people with visual impairments to explore maps, scientific illustrations and circuit diagrams. The pins in the display take form of the programmed image in three dimensions using different level of protrusion. The Kanji characters - adaptations of Chinese characters and used by Japanese people were tested with the 3D tactile display for visually impaired users to identify (Figure 3 - from Summerskill, 2010). 


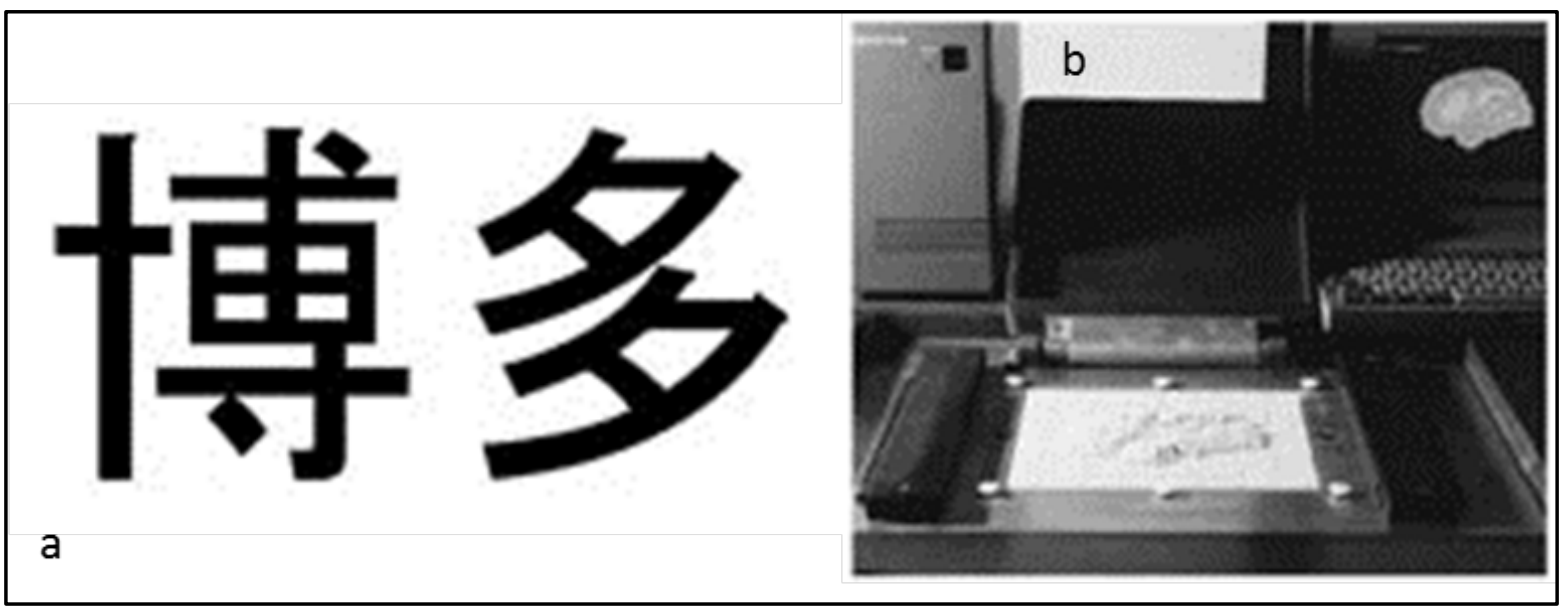

Figure 3. (a) Kanji Symbols and (b) 3D Tactile Pin Display.

Six blind participants were asked to identify 10 of the Kanji symbols. These were presented in three sizes, the larger sizes using more pins in the display and giving a higher resolution. For the small character size $(26 \mathrm{~mm} \times 27 \mathrm{~mm})$ the average response time was slow (32 s) and recognition rate poor (0.63). This improved for the middle sized characters $(51 \mathrm{~mm} \times 52 \mathrm{~mm}$ ) to $17 \mathrm{~s}$ and 0.85 recognition rate, and was best for the largest characters ( $96 \mathrm{~mm} \times 99 \mathrm{~mm}$ ) with $13 \mathrm{~s}$ and 0.93 . This study shows that for complex characters, size and resolution has to be large and high, respectively, if users are to recognise them quickly and accurately.

\section{The importance of invariants symbol identification}

Tactile images are relief form of two dimensional pictures that can be scanned with the fingertips. A relief image can be in different forms and produced in several techniques, however for tactile interpretation it has to be simplified (Eriksson, 1999). A relief image containing too many textures 
(lines, surfaces and dots) will be hard to distinguish by touch so there are certain limitations of patterns that can be used in tactile images. While vision can identify innumerable patterns, the finger can only perceive the difference between textures. Kennedy, Gabias and Nicolls (1991) stated that while feeling a picture, a person can distinguish a swirl of rough or smooth lines or a set of relief or grooved lines, which is irrespective of the pattern. Textures may vary but the lines stay the same. Research conducted on haptic images and textures showed that the invariant descriptor 'rough or smooth' remains the same, in the person's mind, irrespective of the materials used. However the invariants must be distinguishable as 'foreground features' regardless of texture. For example a square must be identifiable by touch as a square regardless of the texture of the material used. According to Eriksson (1999), assigning the few distinguishable tactile symbols for relief images to a particular meaning is not productive. If symbol banks were used, the symbols would not be tied to a particular field of application. Therefore symbol sets are now being devised for the application but for use in various situations. Kennedy et al. (1991) pointed out that studies on comparisons between haptic and optic images have revealed invariants such as 'circle, square, triangle and so on' that are relevant to both touch and vision.

Guidelines for devising tactile symbols

In summary, a set of tactile symbols intelligible should have the following characteristics (Table 1): 
Table 1. Summary of design principles for tactile symbols.

\begin{tabular}{|l|l|}
\hline \multicolumn{1}{|c|}{ Characteristic } & \multicolumn{1}{c|}{ Reference } \\
\hline Use identifiable and familiar shapes. & Loomis and Lederman (1986) \\
\hline $\begin{array}{l}\text { Use simple shapes (since tactile recognition is more limited } \\
\text { than visual). }\end{array}$ & $\begin{array}{l}\text { Eriksson (1999); Gardiner and } \\
\text { Perkins (2002); Gual et al } \\
\text { (2014) }\end{array}$ \\
\hline Consider using outline as well as solid shapes. & Perera (2002) \\
\hline Make the elements of each symbol easily distinguishable. & Stevens and Foulke (1996) \\
\hline $\begin{array}{l}\text { Ensure symbols distinguishable from each other (e.g. shape, } \\
\text { size, texture) but try to ensure a logical formation e.g. filled } \\
\text { square for dark blue, open square for light blue. }\end{array}$ & $\begin{array}{l}\text { Edman (1992); Gardiner and } \\
\text { Perkins (2002); Gual et al. } \\
\text { (2014) }\end{array}$ \\
\hline $\begin{array}{l}\text { Make symbols a suitable size (minimum 10 mm x 10 mm). } \\
\text { Loomis and Lederman (1986); } \\
\text { Pawluk et al. (1998); Gardiner } \\
\text { and Perkins (2002); Perera } \\
\text { (2002); Gual et al. (2014) }\end{array}$ \\
\hline $\begin{array}{l}\text { Avoid over use of surface texture detracting from symbol } \\
\text { recognition. }\end{array}$ & Kennedy et al. (1991) \\
\hline Use different orientations of shape across the symbol set. & Kops and Gardner (1996) \\
\hline In 3D form, ensure suitable height or elevation from surface. & Loomis and Lederman (1986) \\
\hline
\end{tabular}

The characteristics of a process for devising tactile symbols so that they are intelligible by touch should be based upon the above principles. The techniques used depend on the field of application, the user category and available resources in terms of money and skills (Eriksson, 1999). These principles were used in the development of a set of colour symbols, as described in the next section.

\section{Creation of a Colour Symbol Set (CSS)}

An alternative to Braille is to create a symbol system to represent colours with a single symbol per colour. This approach has the benefit that it can be regarded as a simple language that is easy to learn without needing to learn Braille. Symbols can also be learned by sighted young people and can be a shared means of communication. Research has been conducted to create and test a system of symbols 
to help young people identify the colour of different objects (Ramsamy-Iranah, 2015). A key part of the system is that it is designed to be simple and easy to learn since it is based on a relatively small set of symbols to represent principle hues (red, green, yellow, blue, etc.) and tones (light, dark) -see Table 2. The symbols can also be identified whatever their orientation. Referring to the colour communication concept, the LEA Vision Test Systems (Repka, 2002) specifically designed for children and Perera's (2002) notion of tactile perception and spatial acuity, the relief symbols were developed using simplified shapes such as circles, squares, lines, curved lines and dots. The familiarity of these shapes cuts across different pedagogical tools for kindergarten and primary level and also in most research for basic understanding of tactile shapes and their interpretations (McCallum, Ungar, and Jehoel, 2006). As a result of this previous work a symbol set was developed as shown in the Table 2.

Table 2. Symbol set consisting of nine main colours and five tonal variations.

\begin{tabular}{|c|c|c|c|}
\hline Symbol & Colour represented & Symbol & Colour represented \\
\hline & Red & & White \\
\hline & Blue & & Black \\
\hline & Yellow & & Sky Blue \\
\hline & Green & & Light Pink \\
\hline & Orange & & Fuschia \\
\hline & Purple & & Apple Green \\
\hline & Brown & & Grey \\
\hline
\end{tabular}




\title{
Production processes for the symbols in three materials
}

\author{
Production process for swell paper
}

The symbols were printed on a special type of paper called swell paper. The characteristic of this paper is that it has microcapsules of alcohol embedded in it which burst when exposed to heat and make the surface of the paper swell up (Sheppard and Aldrich, 2000). It has a coating of heat reactive chemicals whereby putting black ink on the paper followed by the heating process enables control over the raised areas. An image can be transferred to the paper using a photocopier, an inkjet printer, a marker or heat pen. Lines and dots are also created by drawing straight onto it using a carbon-based pen on the paper.

Traditionally it was the most common medium for producing maps and symbols for visually impaired people. The vertical elevation height is about $0.5 \mathrm{~mm}$ after the heating process (Gual et al., 2014).

To produce the CSS, Illustrator $5.0^{\mathrm{TM}}$ was used. The symbols were created with black lines and drawing tools used to manipulate the boldness, width and stroke of shapes. The symbols were then printed on A4 swell paper with a laser printer then passed through a swell form graphic machine called a fuser. This machine has been specifically designed to process swell-touch paper: heating the paper to the correct temperature to puff up the black ink creating the tactile relief and leaving the rest of the paper flat. The symbols were then cut out and mounted on card (Figure 4) in a random order.
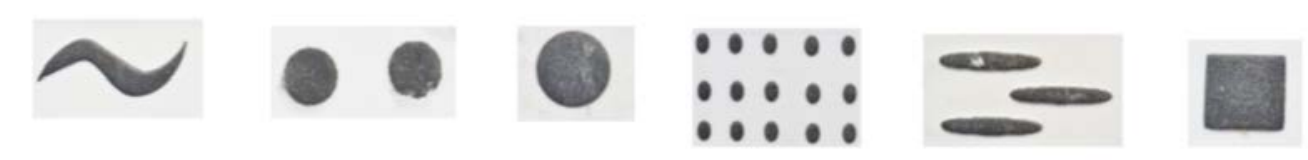

Figure 4. Examples of swell paper symbols. 


\section{Production process for embroidered symbols}

The personal embroidery design software system called PE-DESIGN PLUS was used to convert the symbols from JPEG to PES format that could be transposed into embroidered shapes in a computerised Brother sewing machine. The software has a selection of stitches and sewing attributes that could be manipulated to achieve an embossed effect (Figures 5a and 5b).

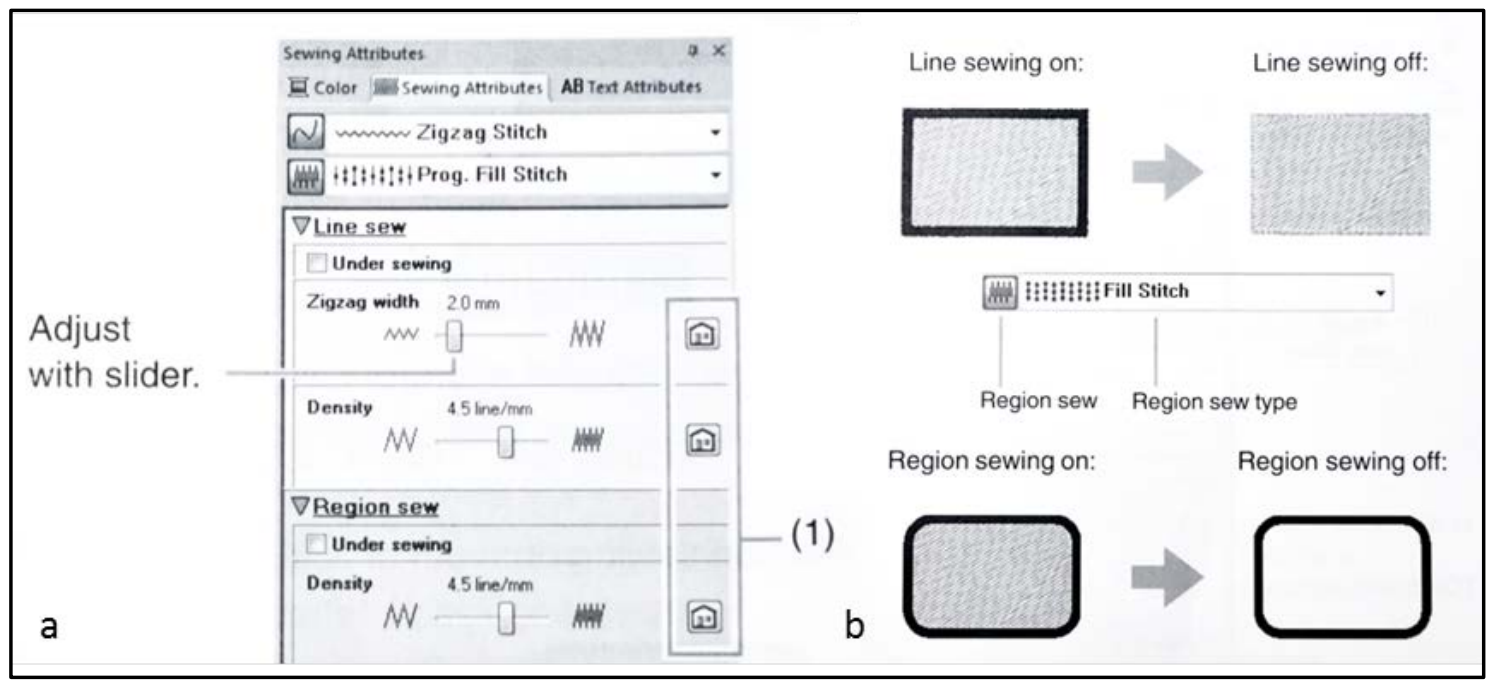

Figure 5. (a) Control panel for stitch selection and (b) Selection of outline for emphasis.

The region fill in the sewing attribute features allow the use of the zig-zag or fill stitch to create either outlines or bold effect of shapes (Figure 5b). A shape can have a distinctive border to emphasize the type of stitches inside. The zig-zag width with the wide type of $5 \mathrm{~mm}$ and a fine density were mostly used for all symbols

Some symbols were placed at a reasonable distance on a single page representing the dimension of the embroidery loop frame so that stitching is coherent on a piece of fabric in the machine (Figure 6). 


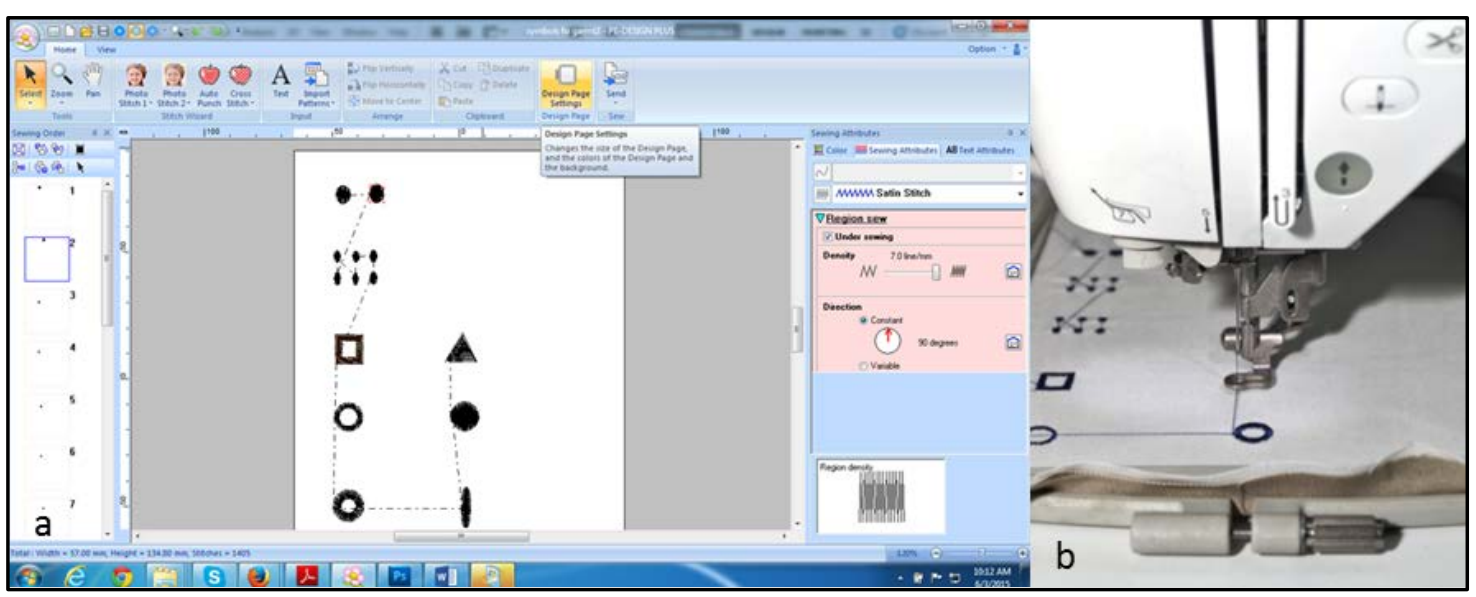

Figure 6. (a) Control panel and (b) Machine output of embroidered symbols.

The embroidered symbols were afterwards cut and aligned on an A4 card paper for testing with the participants (Figure 7).
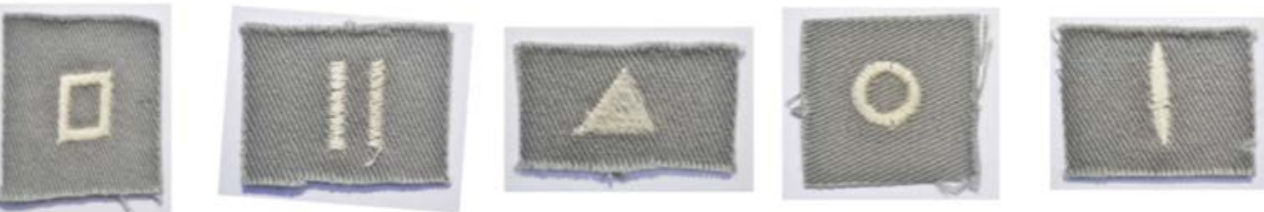

Figure 7. Examples of completed embroidered symbols with border for emphasis.

Process for additive manufactured symbols

The fourteen colour symbols were modelled (Figure 8) using a Computer-Aided Design (CAD) system (SolidWorks ${ }^{\mathrm{TM}}, 2012$ ) and realised with an AM process (fused filament fabrication, MakerBot Replicator $^{\mathrm{TM}} 2$ ). 
A parametric modeller (SolidWorks ${ }^{\mathrm{TM}}, 2012$ ) was used to create sketches of the colour symbols' contours. CAD model geometry was generated to approximately match the geometries of the colour symbols previously formed on swell paper and embroidery. Uniform linear extrusions were performed on all sketches by $2 \mathrm{~mm}$ from their bases. Edges were rounded on some colour symbols if they were considered too sharp; however, some sharp edges were not rounded as they were deemed necessary for symbol recognition. Rectangular bases provided backings to the symbols with their edges distanced $3 \mathrm{~mm}$ from the outermost contours of the colour symbols. These bases were $1 \mathrm{~mm}$ in depth.

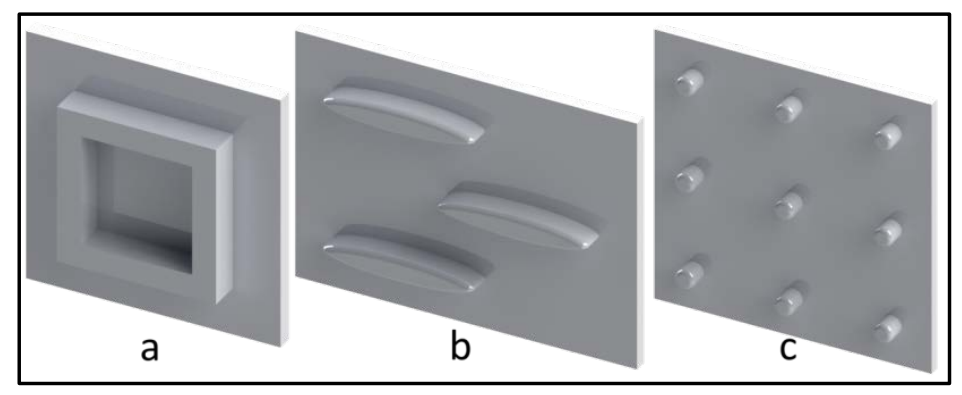

Figure 8. Symbol shapes for: (a) sky blue, (b) purple and (c) yellow.

Symbols representing colours were grouped according to their colour category; primary and secondary colour symbols in one group and tertiary and tonal colour symbols in another group (Figure 9). CAD models were combined to form panels of colour symbols; one panel for each group. Edges of the symbols were extended to a uniform distance to create flush sides on the symbol groups. 


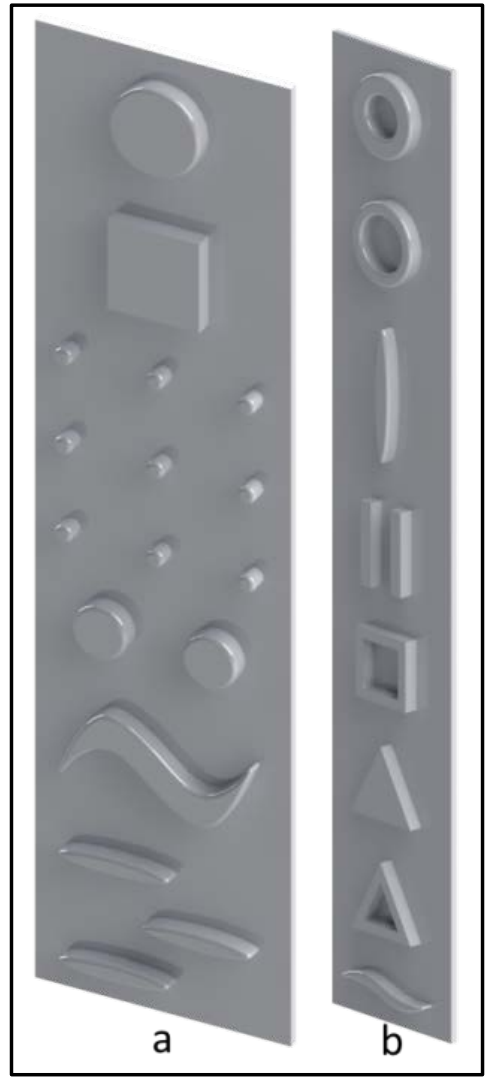

Figure 9. (a) Primary, secondary and (b)

Tertiary and tonal colour symbol groups.

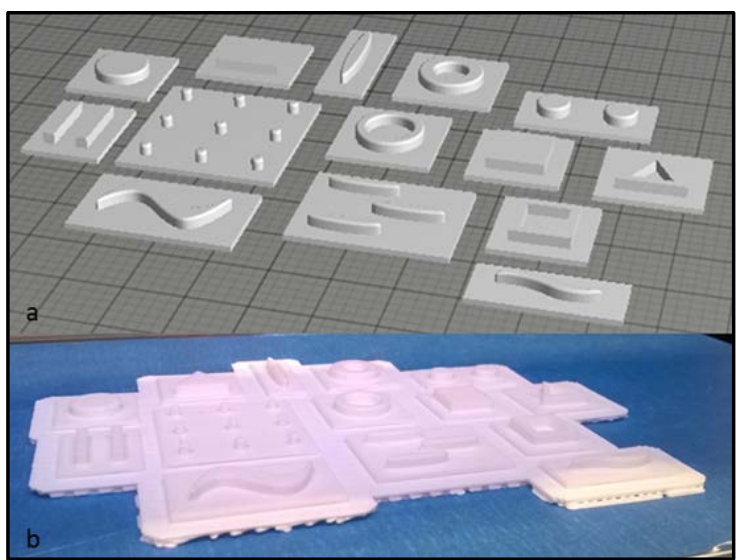

Figure 10. (a) Virtual symbols and (b) Realised colour symbols
Stereolithography (STL) files were generated in SolidWorks ${ }^{\mathrm{TM}}$ in preparation for fabrication. Symbols were arranged, using MakerWare ${ }^{\circledR}$ (2012) software, so their backings were coplanar with the virtual platform (Figure 10a). They were centred and located nearby to one another to reduce fabrication time.

Fused filament fabrication (FFF), an AM process, was used to produce both the individual colour symbols (Figure 10b) and the panels of colour symbols, in 86 and 84 minutes, respectively. A layer height of 0.2 $\mathrm{mm}$ was chosen to account for the division of extrusion distances, and higher resolutions were not required as all sketches of symbols were extruded linearly and vertically.

White AM plastic was used as a neutral and non-distractive colour to create all AM colour symbols layer-by-layer. Additional supporting material was initially laid prior to part fabrication to reduce warping of symbol edges. Supporting material was manually removed post-fabrication. The same fabrication procedure was used to realise the panels of colour symbols. 


\section{Methodology to test and compare the three materials}

A comparison study was carried out to measure the performance of a sample of young people when trying to identify colours in the 14 colour symbol set (CSS) using all three materials described:

- $\quad$ fabric (to represent clothing)

- $\quad$ swell paper (to represent, for example, the colours of a piece of artwork)

- $\quad$ an AM plastic (which would be suitable for children's toys)

Practice in learning the symbols beforehand

Prior to this study, the young people were supported in learning the tactile symbols on swell paper. With the assistance of the teachers, a daily 20-minute slot over a period of 4 weeks was integrated in their pedagogical activities for identifying tactile colours. This allowed the participants to assimilate the new relief symbols and associate them with colours. They had to be guided through the shapes, and be taught by taking their hands and guiding their fingers over the outline of shapes (Eriksson, 1999). The following principles of Mason and McCall (1997), research in the area of tactile perception for visually impaired young people were considered:

1. The teaching of tactile skills in a systematic way at an early age;

2. The mental image building of tactile information is to be conducted gradually.

Other aspects that affect tactile skills were also considered such as the memory span, spatial abilities, fine motor skills and exploratory skills. 


\section{Comparison test process}

In preparation for the test, each set of symbols in the three materials was mounted on an A4 piece of card in randomised order. The test process was then carried out by presenting each set of symbols in turn to a sample of children and young people. Thus each person was presented with 42 symbols at first on the swell paper, then fabric and finally plastic. All participants were asked to recognise the symbols in the three materials in which they were created.

The participants had to recognise the symbols presented in random order and in different orientations. This required the active and scanning movement of the fingers onto the relief symbols to identify the colour. Each child was tested once for each symbol on each type of material. If they guessed the symbols correctly in this first round of testing, the recognition time was recorded. If they struggled to guess one or more symbols, they were retrained until the experimenter was sure that they had been learned and tested again a week later. If correct on this second attempt, the times were recorded.

The participants ( $N=27,15$ male, 12 female) were separated into three, equally-sized age categories with ages ranging between 6 and 20 years old ( $\bar{x}=11.70$, SD 3.46). Each participant was grouped into either a low vision $(\mathrm{N}=19)$, or totally blind $(\mathrm{N}=8)$, group (Table 3 ).

Table 3. Age profile of the participant group $(\mathrm{N}=27)$.

\begin{tabular}{|l|c|c|c|}
\hline Age group & 6 to 10 & 11 to 15 & 16 to 20 \\
\hline Low vision & 6 & 9 & 4 \\
\hline Blind & 6 & 2 & 0 \\
\hline Total & 12 & 11 & 4 \\
\hline
\end{tabular}


This research was carried out respecting all ethical procedures involving human participants whereby caregivers, teachers and parents gave their written consent. The participants were recruited on the basis of visual disability only excluding all other types of physical or mental handicap, from two local blind schools in Mauritius. It is important to note that the sample size is small due to this limitation and that participants selected were Low Vision (LV) and Totally Blind (TB). The Low Vision participants were blindfolded for the tests carried out which is a common practice in studies involving the visually impaired who have common tactile skills and where, for consistency, it is required that the participants do not make use of any partial vision (Reimer and Cox, 2011).

\section{Colour symbol recognition results}

Colour symbol recognition time by touch, in seconds, was used to quantify the ease with which a colour symbol was identified by the participants. The results are shown in Figure 11. 


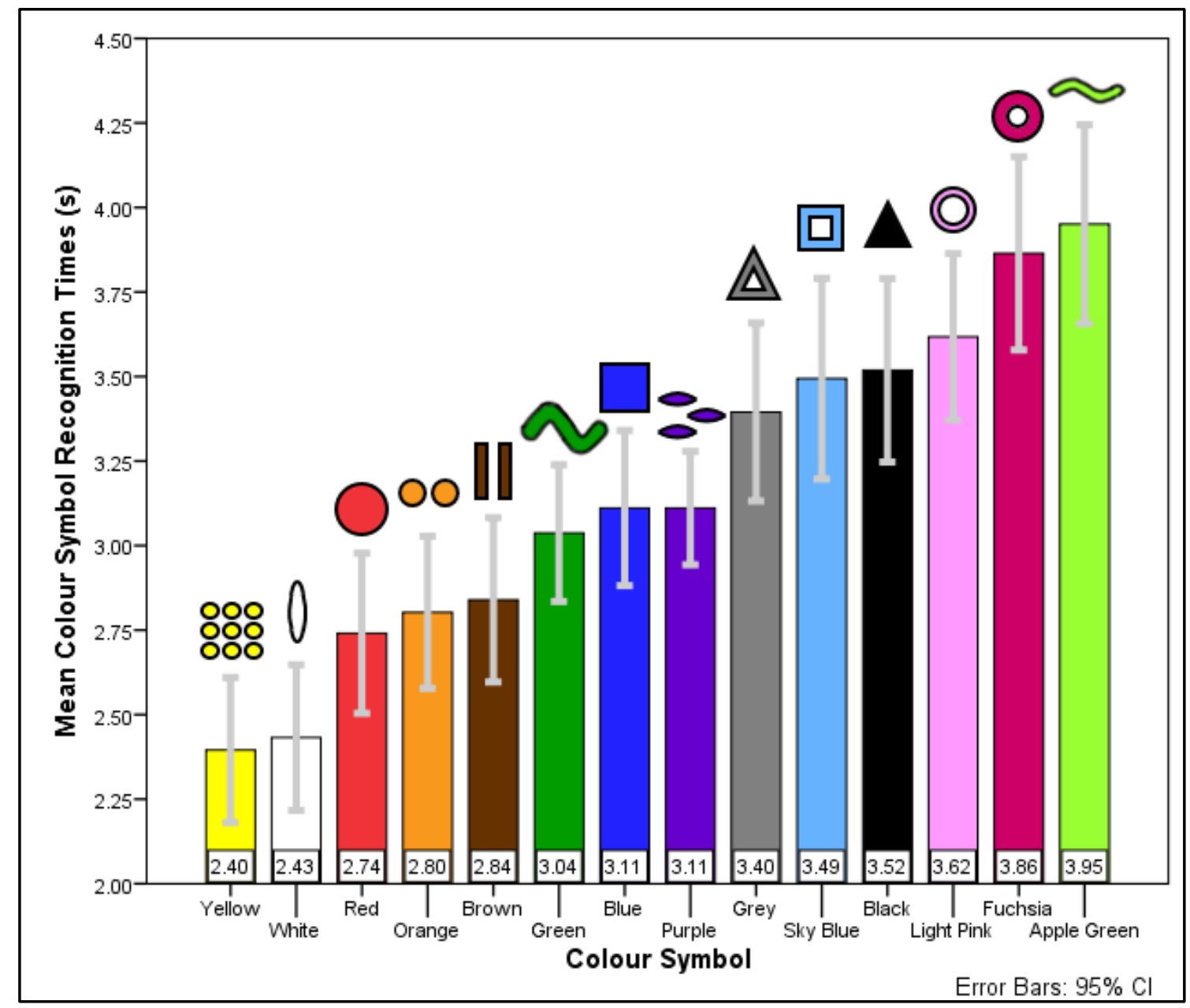

Figure 11. Average recognition times of symbols between symbol geometry.

It can be seen that colour symbol geometry is a contributing factor to recognition time. Where two symbols have the same basic shape but a different border thickness, it is natural that participants will take a little longer to distinguish them than a symbol which is more distinct from the rest of the symbol set. Recognition time for yellow ( $\bar{x}=2.40 \mathrm{~s})$ - the quickest symbol to be identified - was $39 \%$ less than for apple green $(\bar{x}=3.95 \mathrm{~s})$ - the slowest. Statistically significant differences between recognition times of geometry can be observed by comparing the overlap of the confidence interval limits of various 
colour symbol combinations. For example, the lack of overlap between the upper confidence limit for orange and the lower limit for sky blue shows that orange was recognised significantly more quickly than sky blue.

In the following analysis, the average recognition time for each material for all 14 symbols and across all participants, was calculated. The material used for presentation of the symbols was shown to be as influential on recognition time as symbol geometry, since AM plastic symbols $(\bar{x}=2.26 \mathrm{~s})$ were identified $44 \%$ earlier than embroidered symbols $(\bar{x}=4.03 \mathrm{~s}$ ) (see Figure 12 ). A one-way ANOVA highlighted statistical significances $(p=0.000)$ between all three materials, thus suggesting that material selection is a contributing factor to symbol recognition effectiveness. This suggests that the ability of a material to compress, for example, a symbol to retain its form, is a key causal factor of colour symbol recognition time. 


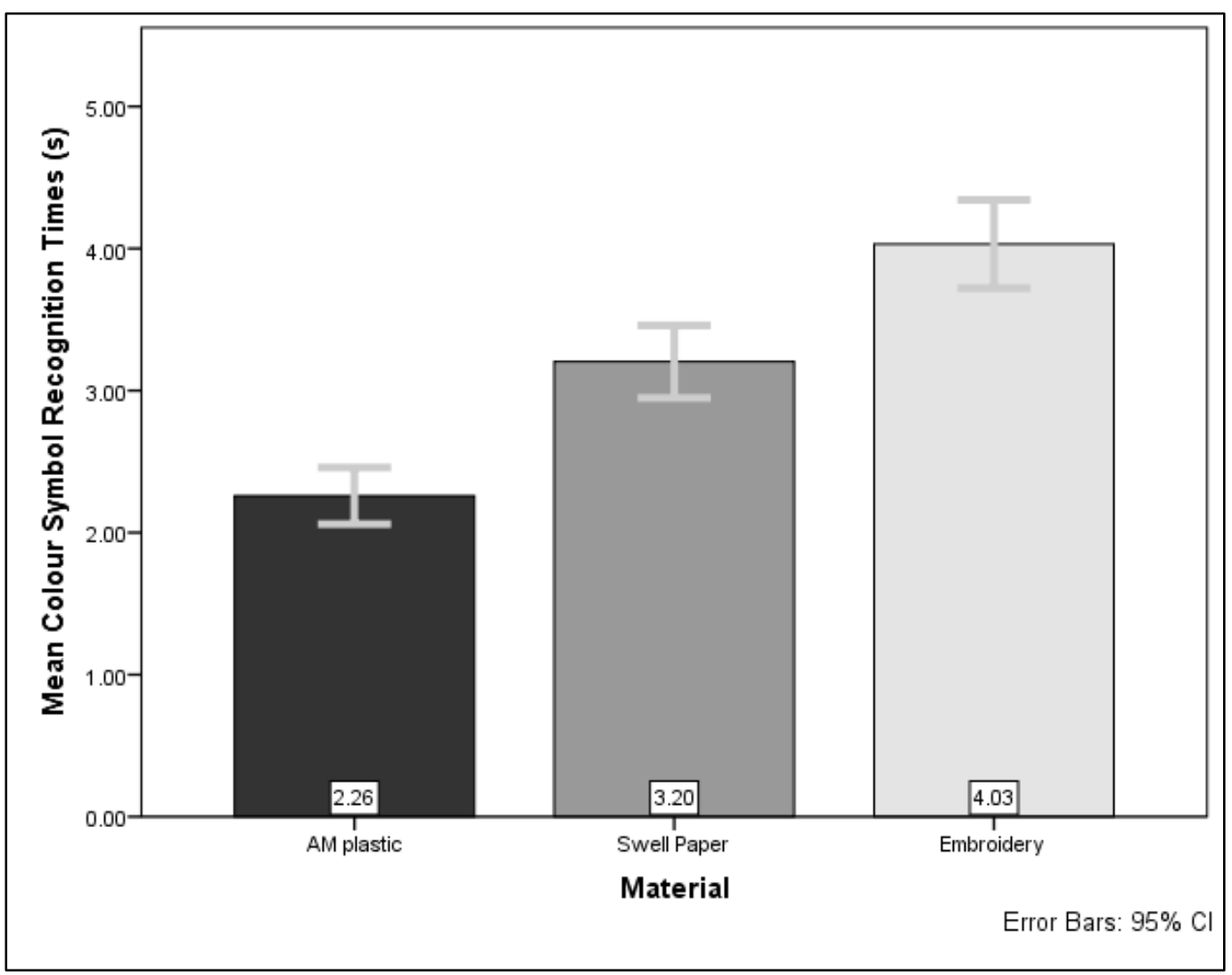

Figure 12. Average recognition times of colour symbols between materials.

The results were also analysed by age group. This shows a similar pattern of recognition times for each medium across the groups (Figure 13) and further demonstrates the importance of material selection to reduce colour symbol recognition time.

Participants in the 6-10 age category, for instance, identified AM plastic symbols ( $\bar{x}=2.51$ s) $25 \%$ quicker than participants in the 16-20 age category took to recognise embroidered symbols $(\bar{x}=3.34 \mathrm{~s})$. Differences of mean recognition time between age categories can also be seen for each material tested; however, older age categories show reduced differences in comparison to the younger age categories. 


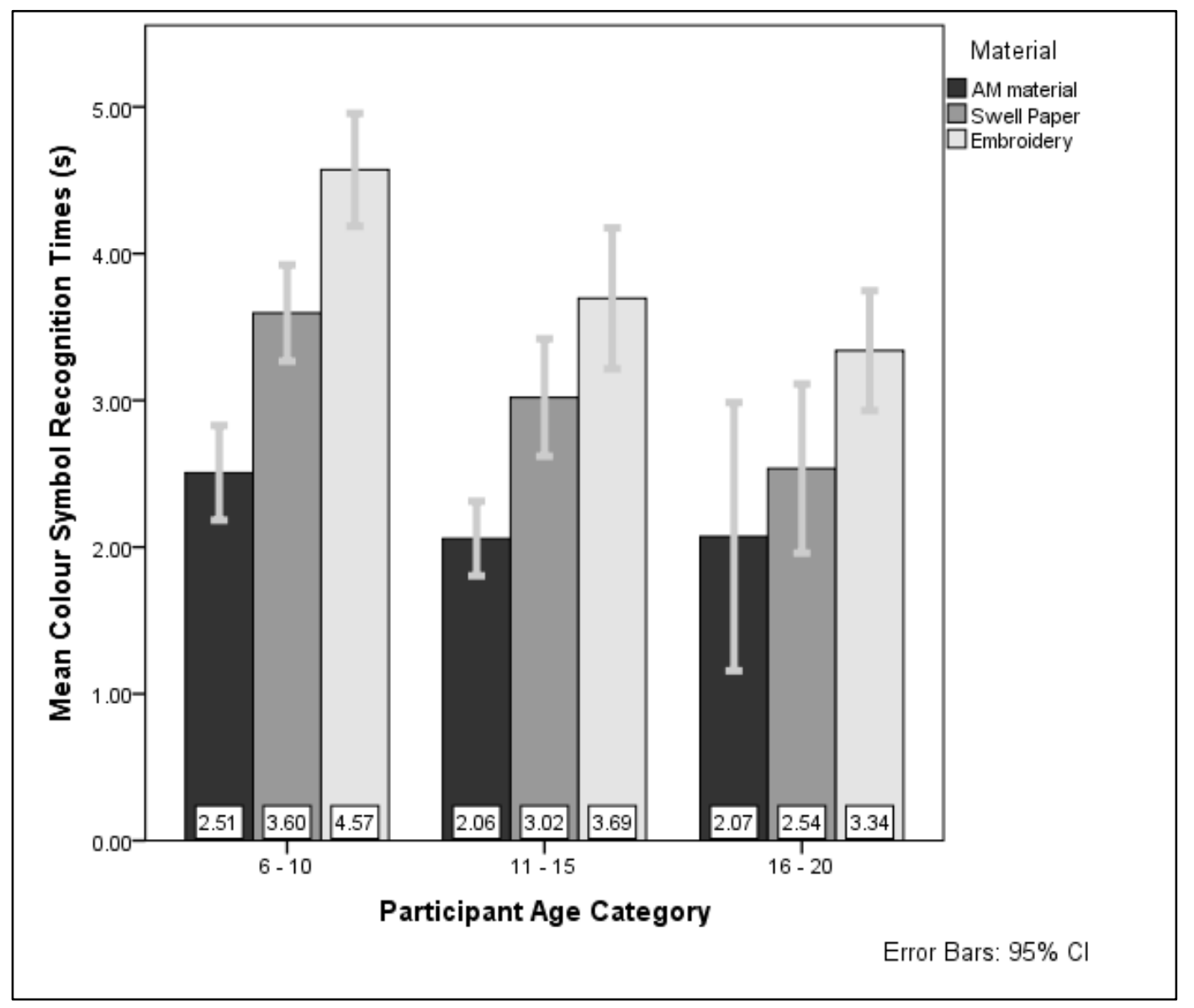

Figure 13. Average recognition times of symbols by age category and material.

Separate one-way ANOVAs were run to highlight significant differences between recognition times of participants of different age categories, for each material. Colour symbol recognition times were significantly different, between all three materials, for younger age participants. Recognition time differences progressively reduced with increasing participant ages, therefore it is suggested that material choice is more important for younger visually impaired people. Colour symbol hardness tests should verify that AM plastic symbols are harder than swell paper symbols which are harder than fabric symbols. This would suggest a direct correlation between symbol hardness, or compressibility, and 
symbol recognisability. The hardness of a symbol also helps to increase the tactile definition of a symbol. Symbols having tall, thin features, constructed using softer materials, may also become progressively more difficult to identify as they become compromised through active touch. Features may elastically deform during active touch and become temporarily unrecognisable, until touch force is reduced. To prevent difficulty in recognition through colour symbol elastic deformation, threedimensional aspect ratios and material hardness should be considered.

Embroidery and thermoform materials showed significant differences $(p=0.002$ and $p=0.004$, respectively) between ages, whereas AM plastic did not $(p=0.069)$. This suggests that AM plastic symbols are more easily recognised across a population, although further testing with a larger sample would be needed to verify this. 


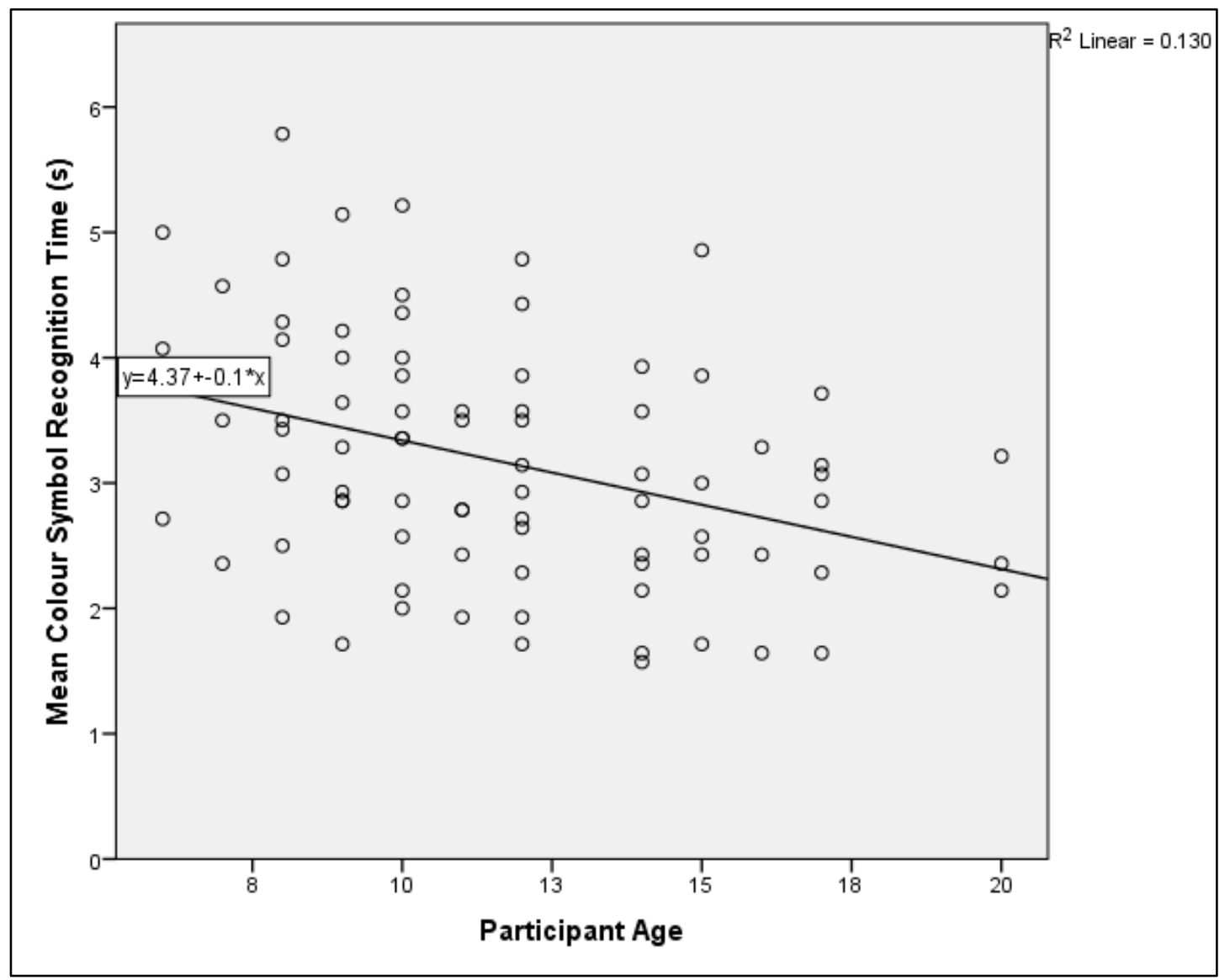

Figure 14. Linear regression of colour symbol recognition times with age.

A set of values (three per participant) were generated for mean symbol colour recognition time across all three materials, and plotted by age (Figure 14). The line of fit shows that participant age affected colour symbol recognition time by 0.1 seconds for each year older a participant is. However, it can be seen by the spread of points either side of the line that the relationship between age and recognition time is weak $\left(r^{2}=0.130\right)$. This correlation may have been clearer if higher levels of data precision were used; recognition time could have been measured to 0.1 second precision and age measured in months rather than years. A larger sample size and a more normal distribution of participant ages may have 
also increased the strength of the correlation. However, data from a sample containing older participants may have reduced the strength of the correlation as average recognition times may increase with participant age.

Different levels of vision and participant gender did not reveal significant differences in recognition times.

\section{Discussion}

The comparison of different materials to represent the colour symbol set (CSS) seems to show that the firmer and more defined tactile feel of AM plastic gave faster recognition times for the participant group of 27 . This might at first imply that this is the preferred material for all situations, given that the cost of AM manufacturing is falling and likely to become as inexpensive as the use of embroidery or swell paper in the future. However another factor is the material to which the symbol is to be applied. For some items, swell paper or embroidery is likely to be more appropriate and comfortable for the person to handle and sense, giving a more seamless feel between the symbol and the item to which it is attached. For softer materials like clothing, for instance, embroidery is still likely to be preferred over hard plastic (although a softer more rubbery material might be acceptable). Following the comparison study, the insights gained helped to develop recommendations for which materials to use for different items that young people commonly use. Table 4 presents a list of such items and indicates what is felt to be the most suitable of the three materials tested for presenting tactile colour symbols.

This research could be extended in several ways. A future study could be to apply the symbols to the objects used in a particular activity such as a game, a wardrobe of clothes or a set of colour coded books to indicate reading level a classroom and to see how well they worked for that activity over a 
period of time. Another area of study would be to adapt the symbol set to children with less developed motor skills for whom the current symbol set might be too small or fiddly. The shapes could be adapted to be made larger and perhaps with the symbol set reduced in number. This would form a stepping stone to using the standard CSS as their skills developed. The CSS could be tested with visually impaired adults to assess whether it would be an effective system of colour communication for them also.

Table 4. Recommended medium for tactile colour symbols for various physical items.

\begin{tabular}{|l|l|c|c|l|}
\hline \multicolumn{1}{|c|}{ Item } & $\begin{array}{l}\text { Embr- } \\
\text { oidery }\end{array}$ & $\begin{array}{c}\text { Swell } \\
\text { paper }\end{array}$ & $\begin{array}{c}\text { AM } \\
\text { plastic }\end{array}$ & \multicolumn{1}{|c|}{ Comment } \\
\hline Pictures in books & & $\checkmark$ & & $\begin{array}{l}\text { Swell paper symbols most suitable for paper books. } \\
\text { Possibly AM plastic for cardboard books. }\end{array}$ \\
\hline Items of clothing & $\checkmark$ & & & $\begin{array}{l}\text { Similarity of embroidery with cloth makes for more } \\
\text { natural feel. }\end{array}$ \\
\hline Play bricks & & & $\checkmark$ & AM plastic would be an ideal material. \\
\hline Play Cards & & $\checkmark$ & & Swell paper would be most suitable. \\
\hline Felt shapes & $\checkmark$ & & & Embroidery on felt would be the optimum choice. \\
\hline $\begin{array}{l}\text { Games e.g. Ludo or } \\
\text { colour matching }\end{array}$ & & & $\checkmark$ & $\begin{array}{l}\text { AM plastic for counters with softer AM materials for } \\
\text { game boards. }\end{array}$ \\
\hline $\begin{array}{l}\text { Crayons or markers } \\
\text { on a plastic palette }\end{array}$ & & & $\checkmark$ & $\begin{array}{l}\text { Narrow surface a challenge for all materials but harder } \\
\text { AM plastics likely to be most effective. }\end{array}$ \\
\hline
\end{tabular}




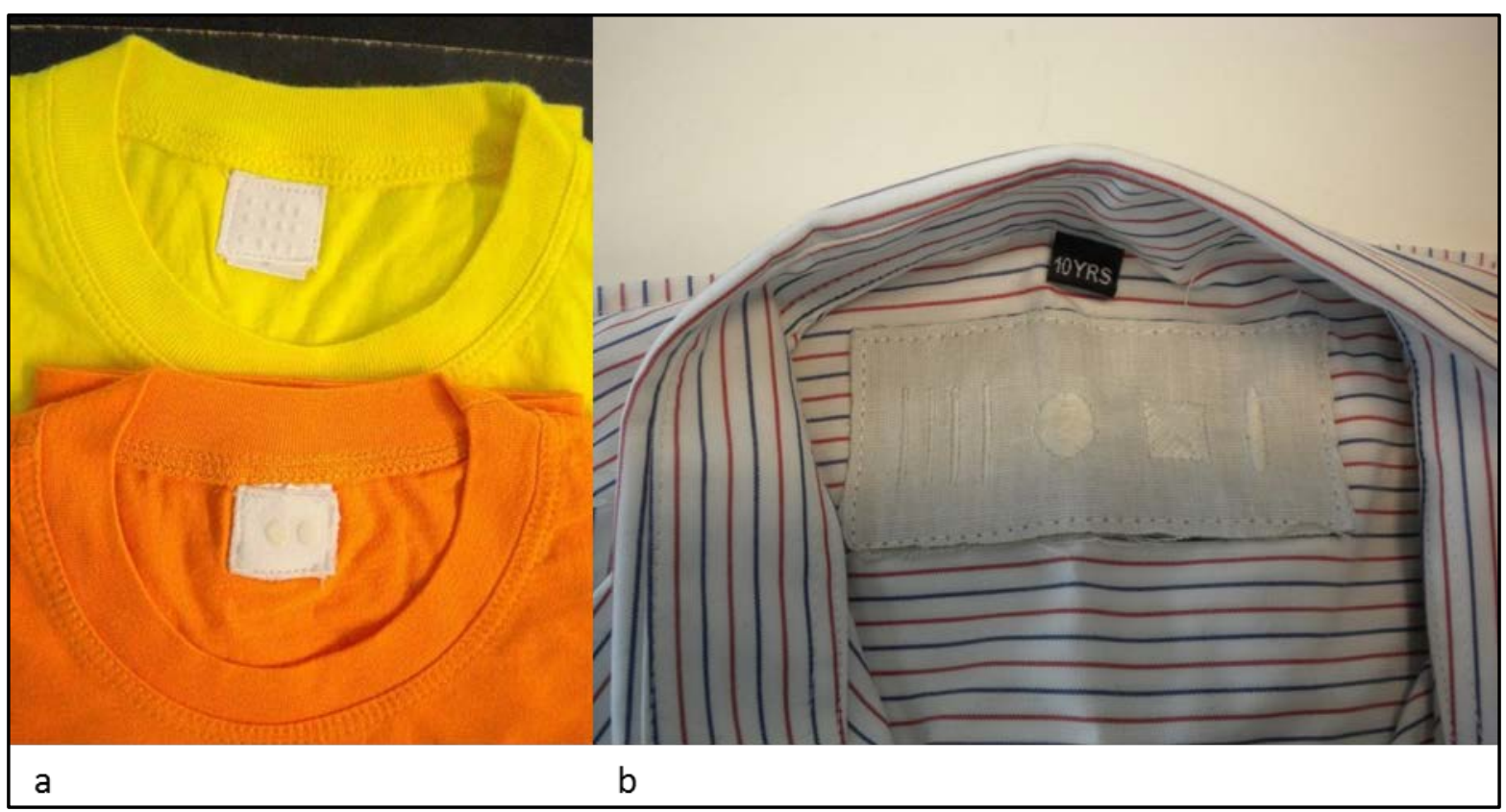

Figure 15. Examples of colour symbols on (a) tee-shirts and (b) a shirt where the first symbol represents the striped pattern - an element of further symbol development.

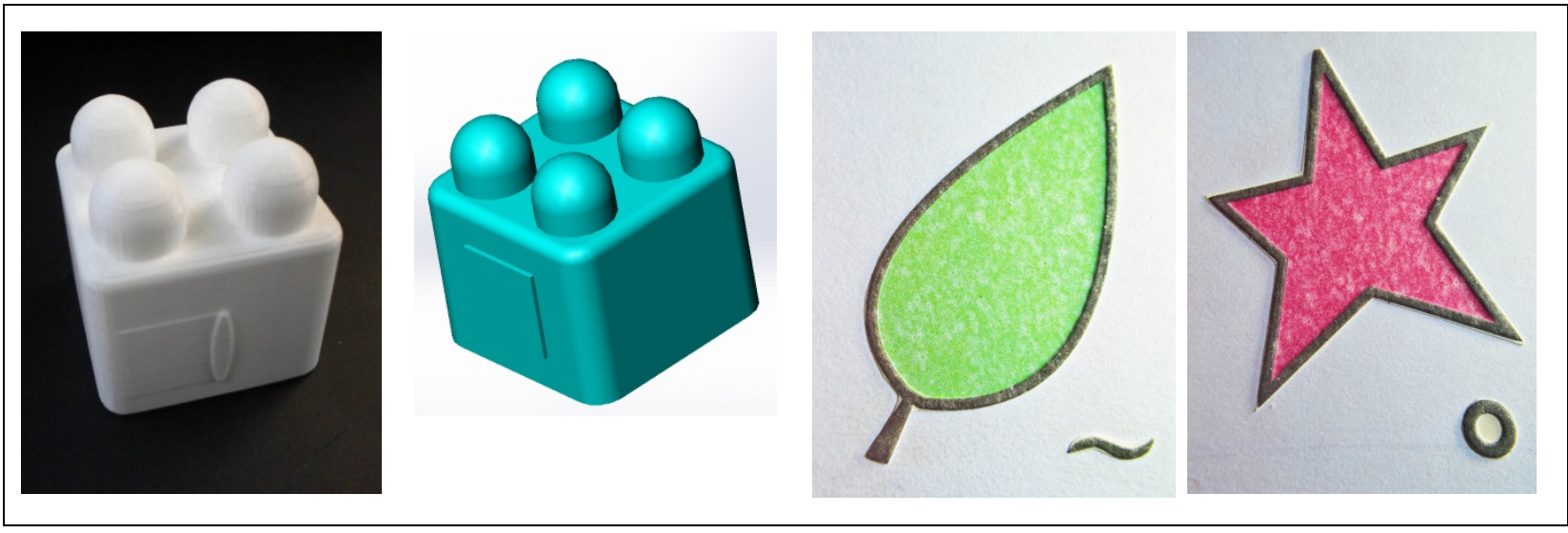

Figure 16. Examples of colour symbols on a play brick (real and virtual) and swell paper on card as part of a shape and colour recognition game. 


\section{Conclusion}

This paper has introduced the colour symbol set (CSS) for visually impaired children and young people to build their confidence in handling colour concepts and promote self-reliance in daily living; enrich their learning experiences and give an extra dimension to the enjoyment of leisure activities. The study has provided an insight into the differences in recognition performance of using different materials to present the CSS colour symbol set. While new and developing processes such as AM offer an effective method for labelling items for recognition of colour by young people with visual impairments, there is still a role for other materials like swell paper and embroidered thread. The use of Additive Manufacturing to produce softer material in the future may offer the combination of efficient colour recognition and a natural feel for items such as clothing and soft play materials. Use of AM may also become a commonplace appliance in the home, allowing parents to produce symbols for their own children and to customise items appropriately so they can identify the colours of the items they use.

\section{References}


Chapman, C. E. (1994). Active versus passive touch: factors influencing the transmission of somatosensory signals to primary somatosensory cortex. Canadian Journal of Physiology and Pharmacology, 72, 5, 558-570.

Edman, P. (1992). Tactile graphics. New York, NY: American Foundation for the Blind.

Eriksson, Y. (1999). How to make tactile pictures understandable to the blind reader. The Swedish Library of Talking Books and Braille.

Future Aids (2015). Retrieved from http://www.braillebookstore.com/Braille-Clothing-Tags,-Colors.2

Gardiner, A. \& Perkins, C. (2002). Best practice guidelines for the design, production and presentation of vacuum formed tactile maps. Tactile Books. Retrieved from http://www.tactilebooks.org/tactileguidelines/page1.htm

Gual, J., Puyuelo, M., \& Llovras, J. (2014). Three-dimensional tactile symbols produced by 3D printing: Improving the process of memorizing a tactile map key. British Journal of Visual Impairment, 32, 3, 263278.

Kennedy, J. M., Gabias, P. \& Nicolls, A. (1991). Tactile Pictures. In M. A. Heller \& W. Schiff (Eds.), The Psychology of Touch, Chapter 11, 263-300. New Jersey: Lawrence Erlbaum Associates Inc.

Kops, C. E. \& Gardner, E. P. (1996). Discrimination of simulated texture patterns on the human hand. Journal of Neurophysiology, 76, 1145-1165.

Loomis, J. M. \& Lederman, S. J., (1986). Tactual Perception. In K. R. Boff, L. Kaufman \& J. P. Thomas (Eds.), Handbook of Perception and Human Performance, Vol. II, Cognitive Processes and Performance, Chapter 31 (1-41) New York: John Wiley. 
McCallum, D., Ungar, S., \& Jehoel, S. (2006). An evaluation of tactile directional symbols. British Journal of Visual impairment, 24, 2, 83-92.

MakerWare ${ }^{\circledR}$ (2012). Edition: 2.4.1.24, Brooklyn, NY: MakerBot Software Team.

Mason, H., \& McCall, S. (Eds.) (1997). Visual impairment: Access to education for young people and young people. New York: David Fulton.

Millar, S. \& Al-Attar, Z. (2003). How do people remember spatial information from tactile maps? British Journal of Visual Impairment, 21, 2, 64-72.

Pawluk, D., Van Buskirk, C., \& Killebrew, J. (1998). Control and pattern specification for a high density tactile display. $7^{\text {th }}$ Haptic Symposium, Anaheim, California, USA.

Perera, S. (2002). Tactile perception and design. Tiresias Scientific Research Reports. 1-14. Retrieved from http://www.tiresias.org/research/reports/tpd1.htm

Perkins, C. (2002). Cartography: Progress in tactile mapping. Progress in Human Geography, 26, 521530.

Ramsamy-Iranah, S. (2015). Development of assistive tactile symbols for colour recognition by the visually impaired children and young people, PhD thesis, Department of Applied Sustainability and Enterprise Development, Faculty of Engineering, University of Mauritius (In progress).

Reimer, A. M. \& Cox, R. F. A. (2011). Improvement of fine motor skills in children with visual impairment: An explorative study. Research in Development Disabilities, 32, 1924-1933.

Repka, M. X. (2002). Use of LEA symbols in young children. British Journal of Ophtalmology, 86, 5, 489490. 
Sheppard, L. \& Aldrich, F. (2000). Tactile graphics: A beginner's guide to graphics for visually impaired young people. Primary Science Review, 65, 29-30.

Shimojo, M., Shinohara, M., \& Fukui, Y. (1999). Human shape recognition performance for 3-D tactile display, IEEE Transactions on Systems, Man, and Cybernetics - Part A: Systems and Humans, 29, 6, 637-644.

SolidWorks ${ }^{\mathrm{TM}}$ (2012). Student edition, Academic year 2013-2014, Waltham, MA: Dassault Systèmes.

Summerskill, S. J. (2010). The tactile sense as a mechanism for the reduction of visual load elicited by control interactions: An automotive case study approach to the development of genetic design recommendations, PhD Thesis, Department of Design and Technology, University of Loughborough, United Kingdom.

Steinkuller, P. G., Du, L., \& Gilbert, C. (1999). Childhood blindness, Journal of American Association for Pediatric Ophthalmology and Strabismus, 3, 26-32.

Stevens, J. C. \& Foulke, E. (1996). Tactile acuity, aging and Braille reading in long-term blindness. Journal of Experimental Psychology: Applied, 2, 2, 91-106. Retrieved from www.braille.org/papers/acuity

Todorovic, D. (2008). Gestalt principles. Scholarpedia, 3, 12, 5345. Retrieved from http://www.scholarpedia.org/article/Gestalt_principles

World Health Organisation (2014). Priority eye diseases: Main causes of visual impairment. Retrieved from http://www.who.int/blindness/causes/priority 